\title{
Simulation of parthenium weed canopy under changing climate using L-systems
}

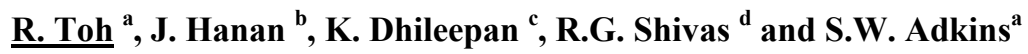 \\ ${ }^{a}$ The University of Queensland, Tropical and Subtropical Weeds Research Unit, School of Agriculture and \\ Food Sciences, St Lucia, QLD 4072, Australia \\ ${ }^{b}$ The University of Queensland, Alliance for Agriculture and Food Innovation, Biological Information \\ Technology, St Lucia, QLD 4072, Australia \\ ${ }^{c}$ Invasive Plant Science, Biosecurity Queensland, Department of Employment, Economic Development and \\ Innovation, 41 Boggo Road, Dutton Park, QLD 4102, Australia \\ ${ }^{d}$ Plant Biosecurity Science, Biosecurity Queensland, Department of Employment, Economic Development \\ and Innovation, 41 Boggo Road, Dutton Park, QLD 4102, Australia \\ Email: ruey.toh@uqconnect.edu.au
}

\begin{abstract}
Parthenium weed (Parthenium hysterophorus L.) is an erect, branched, annual plant of the family Asteraceae. It is native to the tropical Americas, while now widely distributed throughout Africa, Asia, Oceania, and Australasia. Due to its allelopathic and toxic characteristics, parthenium weed has been considered to be a weed of global significance. These effects occur across agriculture (crops and pastures), within natural ecosystems, and has impacts upon health (human and animals). Although integrated weed management (IWM) for parthenium weed has had some success, due to its tolerance and good adaptability to temperature, precipitation, and $\mathrm{CO}_{2}$, this weed has been predicted to become more vigorous under a changing climate resulting in an altered canopy architecture. From the viewpoint of IWM, the altered canopy architecture may be associated with not only improved competitive ability and replacement but also may alter the effectiveness of biocontrol agents and other management strategies.
\end{abstract}

This paper reports on a preliminary study on parthenium weed canopy architecture at three temperature regimes (day/night $22 / 15^{\circ} \mathrm{C}, 27 / 20^{\circ} \mathrm{C}$, and $32 / 25^{\circ} \mathrm{C}$ in thermal time $12 / 12$ hours) and establishes a threedimensional (3D) canopy model using Lindenmayer-systems (L-systems). This experiment was conducted in a series of controlled environment rooms with parthenium weed plants being grown in a heavy clay soil. A sonic digitizer system was used to record the morphology, topology, and geometry of the plants for model construction.

The main findings include the determination of the phyllochron which enables the prediction of parthenium weed growth under different temperature regimes and that increased temperature enhances growth and enlarges the plants canopy size and structure. The developed 3D canopy model provides a tool to simulate and predict the weed growth in response to temperature, and can be adjusted for studies of other climatic variables such as precipitation and $\mathrm{CO}_{2}$. Further studies are planned to investigate the effects of other climatic variables, and the predicted changes in the pathogenic biocontrol agent effectiveness.

Keywords: $\quad$ Parthenium weed, changing climate, canopy architecture, 3D canopy model, L-systems 


\section{INTRODUCTION}

In general, temperature, precipitation and atmospheric $\mathrm{CO}_{2}$ (carbon dioxide) are considered to be climatic variables that alter plant invasiveness (Bradley et al., 2010). As a noxious and invasive species in numerous countries across Africa, Asia, Oceania, and Australasia, parthenium weed (Parthenium hysterophorus L.) is suggested to be physiologically adaptable and thereby tolerant to a wide range of temperature regimes, lower rainfall, and elevated $\mathrm{CO}_{2}$ (Dale, 1981; Doley, 1977; Hegde and Patil, 1980; Navie et al., 2005). Besides this tolerance characteristic, parthenium weed has been suggested to be more vigorous and prolific under a changing climate with an altered canopy architecture that may be associated with higher competitiveness (Navie et al., 2005) or in other words 'invasiveness' (Manea \& Leishman, 2010). In terms of integrated weed management (IWM), this change in physiology and morphology of parthenium weed, creates a question, how effective will the current biocontrol agents be in the future?

In terms of phytopathology, it has been suggested that an enlarged plant canopy size and modified architecture (Idso and Idso, 1994; Matros et al., 2006) will be beneficial to the pathogenic biological control agent and result in a higher disease severity (Chakraborty, 2005; Manning and Tiedemann, 1995; Pangga et al., 2011). Relevant studies on plant architecture changes have been undertaken on economic crop species however little is known about weed species. In order to determine how environmental factors affect parthenium weed canopy architecture and to further understand the indirect effects on pathogenic biocontrol agents (ie. summer rust), this paper conducts a preliminary study on the parthenium weed canopy architecture grown under three temperature regimes. Moreover, a three-dimensional (3D) canopy model using Lindenmayer-systems (L-systems) was developed, to provide a clearer visual presentation and as a tool for future studies on other climatic variables, pathogens and competitiveness.

\subsection{Morphology of parthenium weed}

Parthenium weed is an erect, branched, and deep taprooted annual Asteraceae herb (Navie et al 1996). Like many other Asteraceae species, the life cycle of parthenium weed has three distinct stages: seedling, rosette and adult stages. The seedling stage (Figure 1a) consists of seedlings with two small, hairless cotyledons with short petioles (Navie et al. 1996). This is followed by a rosette stage (Figure 1b) which has pubescent and deeply lobed leaves (Navie et al. 1996). The rosette stage is terminated when internode extension occurs creating an erect stem on which new leaves grow (smaller, narrower and less lobed than rosette leaves, but still pubescent). These leaves are inserted alternately on the pubescent and rigid main and side stems. The formation of capitula (Figure 1c) is initiated at the terminal leaf axil and then progressively moves downwards over the lateral branches (Navie et al. 1996). These numerous capitula (flower heads) are grouped in branched clusters on stalks (Figure 1d), which arise from the leaf axils at the top of the plant (Navie et al. 1996). Each flower head forms five cypselae (fruit) (Figure 1e), each consisting of two sterile florets and scales, and a single black and flattened seed (Navie et al. 1996). Parthenium weed plants can grow up to $2 \mathrm{~m}$ high, though $1.5 \mathrm{~m}$ is most common (Navie et al. 1996).

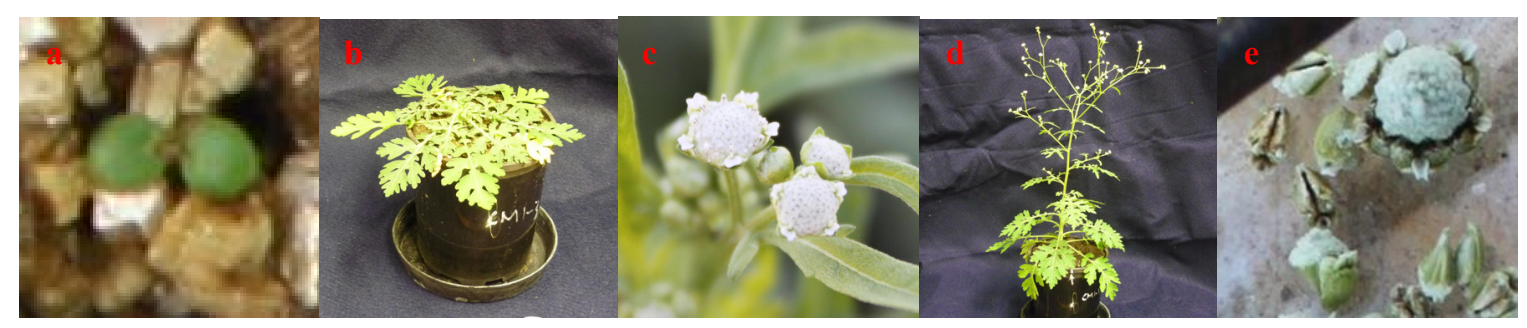

Figure 1. Distinct parthenium weed morphological stages from seedling (a), rosette (b), flower heads (c) formation (d), and to fruits (e).

\subsection{The modelling approach}

In phytopathology, canopy structure has been demonstrated to harmonise or to mediate the impact of external climatic conditions, thereby altering the microclimate (ie. temperature and relative humidity) which results in changed pathogen dynamics and/or disease incidence (Pangga et al., 2011). In order to help understand this, computational modelling is considered to be a tractable and realistic tool to examine hypotheses that relate to the canopy structure and phytopathology (Ress and Lawton, 1993). In recent research (Drouet and Pagès, 2007; Pachepsky et al., 2004; Pangga et al., 2011), functional-structural plant models or 'virtual plants', have been commonly used for presenting both the functional and the structural development of plants in three-dimensional (3D) space (Hanan and Prusinkiewicz, 2008). Many models are 
based on Lindenmayer-systems (L-systems) formalism (Lindenmayer, 1968a; Lindenmayer, 1968b), which will be used for modelling and simulating canopy architecture in this study.

\section{MATERIALS AND METHODS}

Parthenium weed architecture was studied in plants growing under three temperature regimes (day/night $22 / 15{ }^{\circ} \mathrm{C}, 27 / 20{ }^{\circ} \mathrm{C}$, and $32 / 25{ }^{\circ} \mathrm{C}$ ). These regimes represented typical warm, intermediate, and cool conditions under which parthenium weed grows. These conditions were created by three controlled environment rooms each with a light of $250 \mathrm{umol} \mathrm{s}^{-1}$, a photoperiod of 12 hours and a relative humidity of $65 \%$.

Seed of parthenium biotype 'Clermont' was collected directly from mature parthenium weed plants growing in Northbrook Creek, Queensland, and subsequently dried and kept at $4{ }^{\circ} \mathrm{C}$ prior to this study. Seed was germinated on a tray of Premium General Mix in a growth chambers with a day/night temperature of $27 / 20{ }^{\circ} \mathrm{C}$. At the eight leaf stage (c. 28 days after germination), plants with uniform architecture were selected for transplantation. Each plant was then transplanted to a pot fully filled with heavy clay soil collected from Gatton, Queensland. Six transplanted plants were grown under each temperature regime. Watering was done once every 3 days.

\subsection{Data processing and analysis}

Plant development was tracked using 3D digitising (Room et al. 1996) every third day with a sonic digitizer (Freepoint 3D, Scientific Accessories Corporation / GTCO CalComp), where the first measurement commenced on the ninth day after transplantation and the last measurement was finalised after c. 550 growing degree-days (GDD) of thermal time (Trudgill et al., 2005). Digitised points were used to calculate the internode and petiole length and leaf length and width. Growing Degree Days (GDD) were calculated for each temperature regime based on the following equation:

$$
G D D=\frac{T \max +T \min }{2}-\text { Tbase }
$$

$T_{\max }$ and $T_{\min }$ are the maximum and minimum temperatures in each day where the plant grows and develops. $T_{\text {base }}$ is the base temperature of plant growth and development. Although the base value has not been tested for this biotype, $10^{\circ} \mathrm{C}$ is the generally accepted minimum temperature for parthenium weed development (Navie et al, 1996) and is therefore used in this study.

Phyllochron, the speed of plant growth and development, was calculated by dividing the GDD cumulative between appearance of the first leaf initiated at the transplanting and the last leaf, by the number of leaves appearing during this time. Growth durations for internodes and leaves were determined as the difference between the cumulative GDDs at the time of the appearance of the organ and the time of the first measurement at its maximum value. Number of leaves and nodes, and length of internode and leaf components were recorded to compare the temperature effect on canopy architecture and to generate the parameter inputs for modelling.

\subsection{Architectural modelling}

In L-systems, a plant is represented by a sequence of component modules that consist of symbols and associated numeric parameters (Hanan, 1997). Plant growth and development are formed and enabled by production rules applied in a series of time steps (Hanan, 1997). A production rule is expressed as follows:

$$
\text { predecessor : condition } \rightarrow \text { successor }
$$

where 'predecessor' is the module to be replaced, 'successor' is a string of modules representing the result at the time step, and 'condition' is a logical expression determining whether the predecessor is applicable at the time step.

In this study, degree-day and node were the main parameters to control maximum growth and to initiate new growth when the phyllochron was reached. Growth expression of internode (length) and leaf (length, width and petiole length) was modelled empirically using average growth duration. Leaves (excluding petioles) were modelled as diamond-shaped polygons. 


\section{RESULTS}

\subsection{Phyllochron}

It was found that under these three temperature regimes plant growth and development were highly correlated to growing degree-days. The phyllochron of parthenium weed can therefore be presented as a good linear fit to growing degree-days (Figure 2).

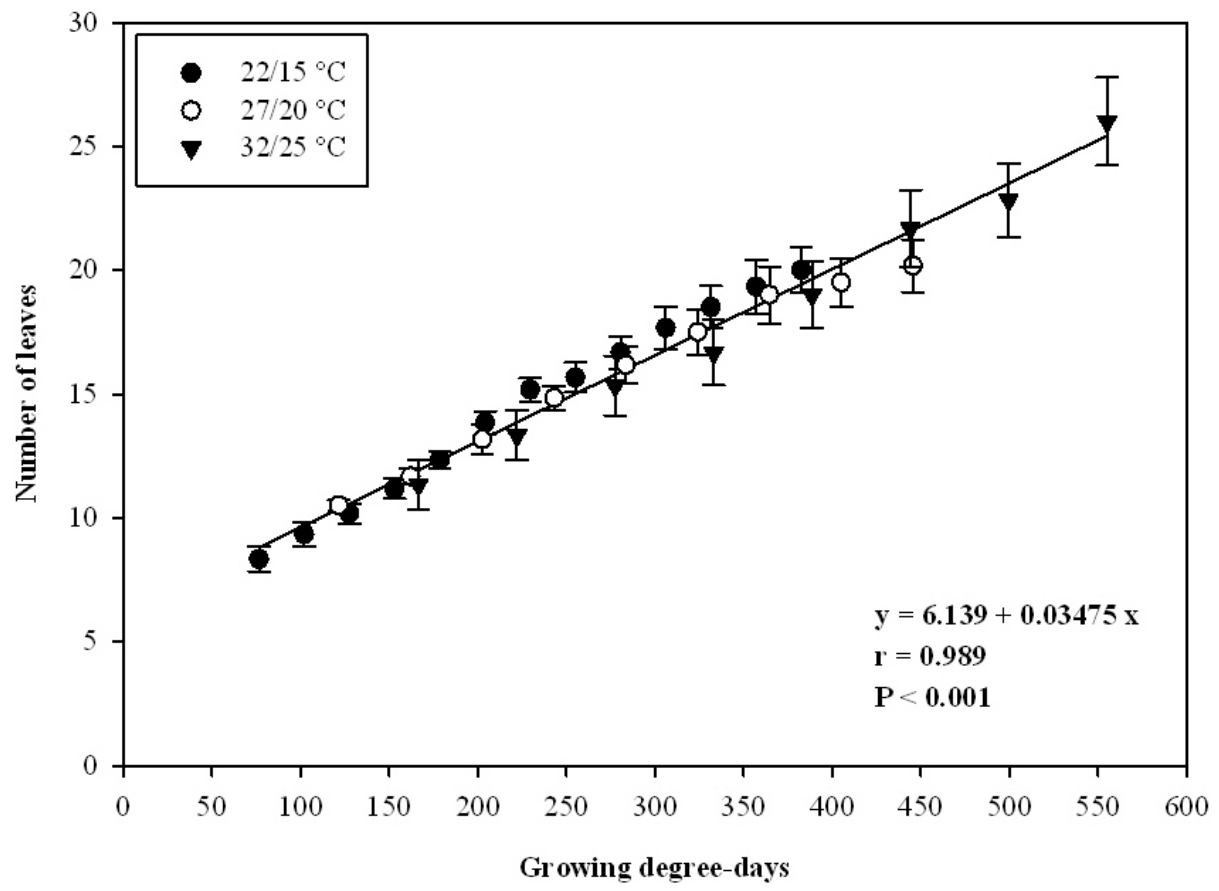

Figure 2. The relationship between GDD and number of leaves represents the phyllochron $(\mathrm{N}=6)$.

\subsection{Leaf}

Comparison of leaf growth based on temperature effect was achieved by looking into the growth trends of the leaves (\#12,\#14, \#16, and \#18) in each temperature regime (Figure 3). In general, leaves appeared at a similar time (GDD) having a similar length, while the maximum leaf length in Temperature $3\left(32 / 25{ }^{\circ} \mathrm{C}\right)$ was greater than others. 

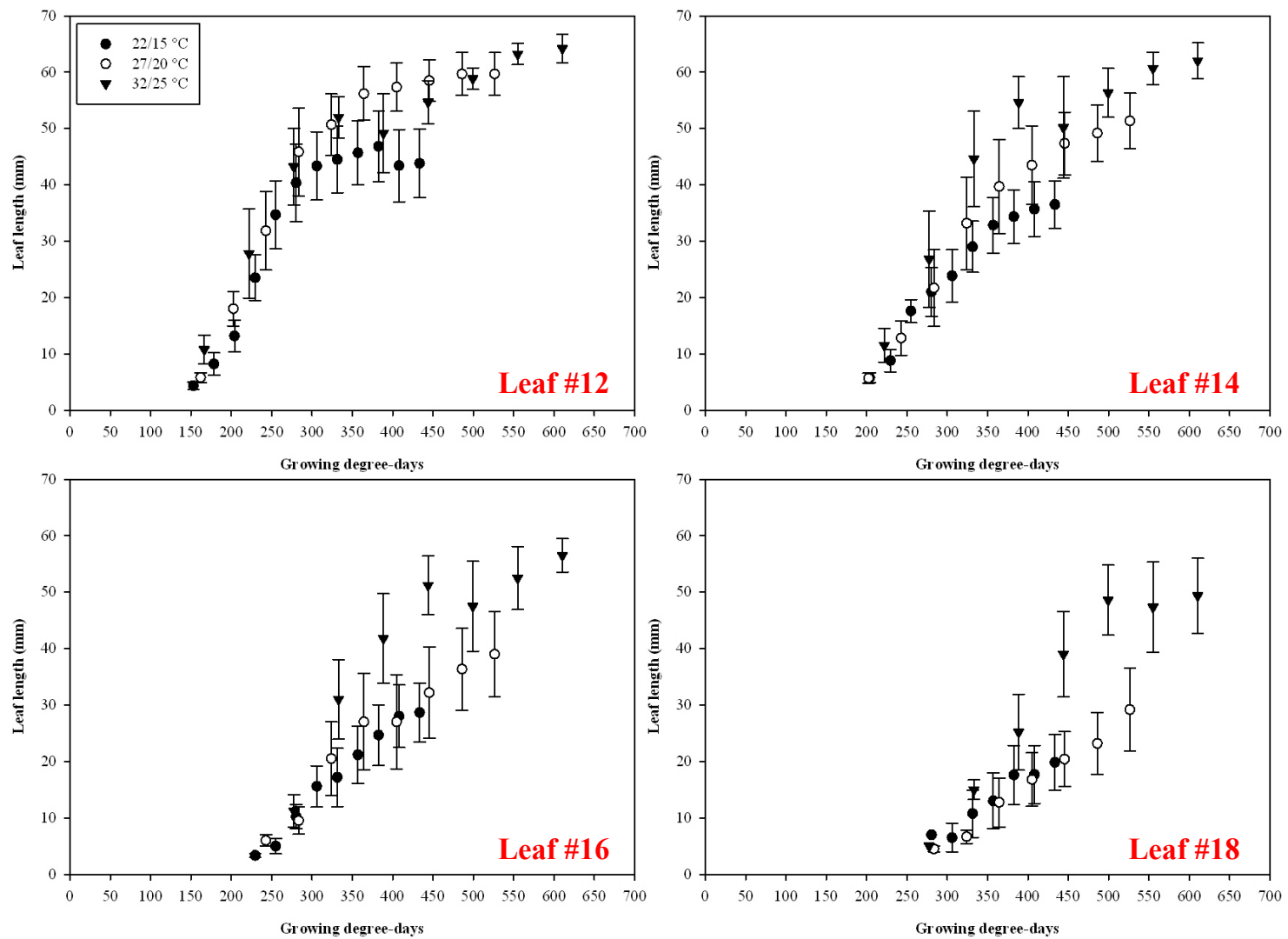

Figure 3. Leaf length comparison for three temperature regimes, specifically on four sampled leaves $(\mathrm{N}=$ $6)$.

\subsection{Internode}

Maximum length of internodes (Figure 4) shows that in general earlier (older) internodes were shorter than later (younger) internodes.

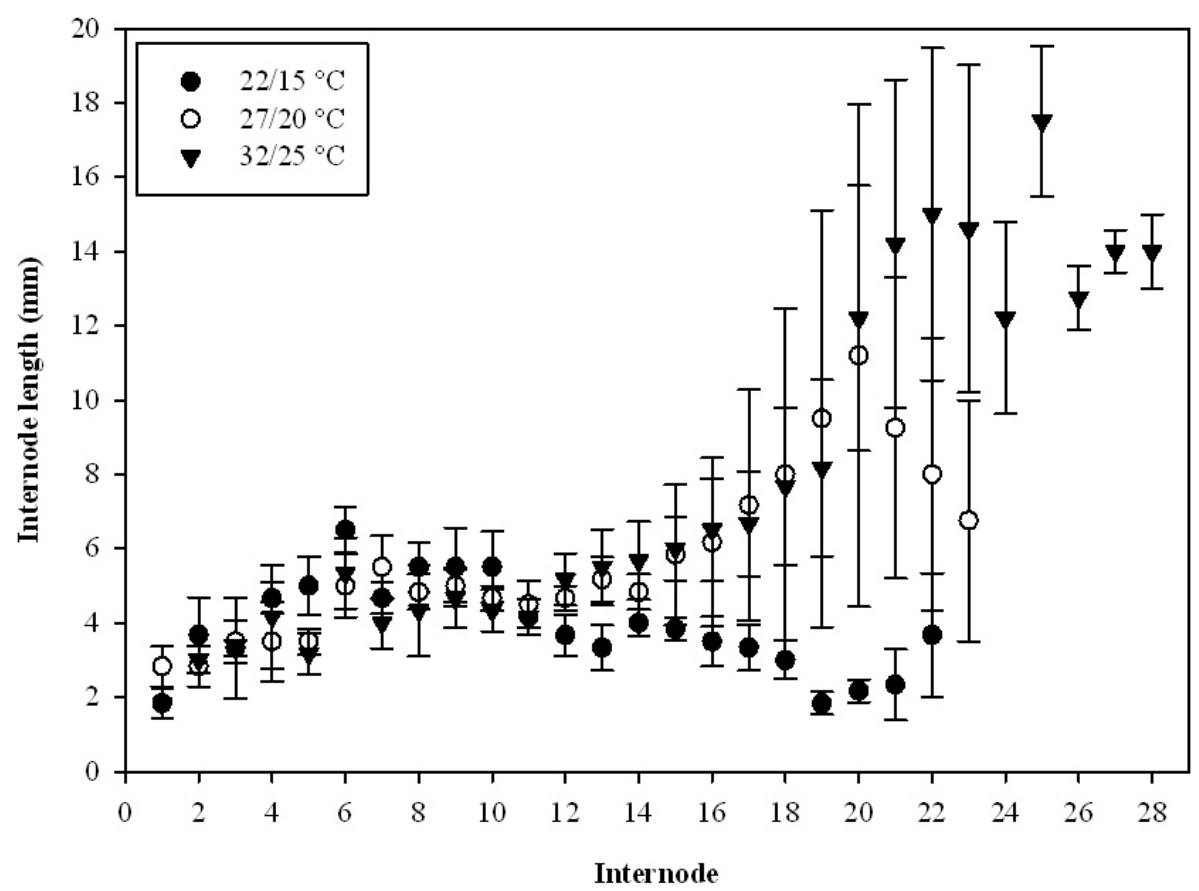

Figure 4. Maximum internode length of each internode by temperature treatment $(\mathrm{N}=6)$. 


\subsection{Model visualisation}

A virtual 3D canopy architecture model of parthenium weed plant was developed using L-systems based on the empirical data. Side-view and top-view of plant under three temperature regimes and at different days (Figure 5) suggest an apparent difference on parthenium weed canopy size and structure upon temperature effect.

Day 20

$27 / 20{ }^{\circ} \mathrm{C}$
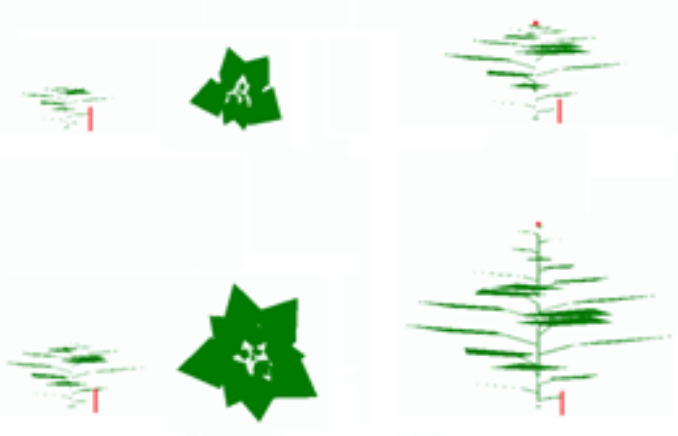

Day 32

$22 / 15^{\circ} \mathrm{C}$
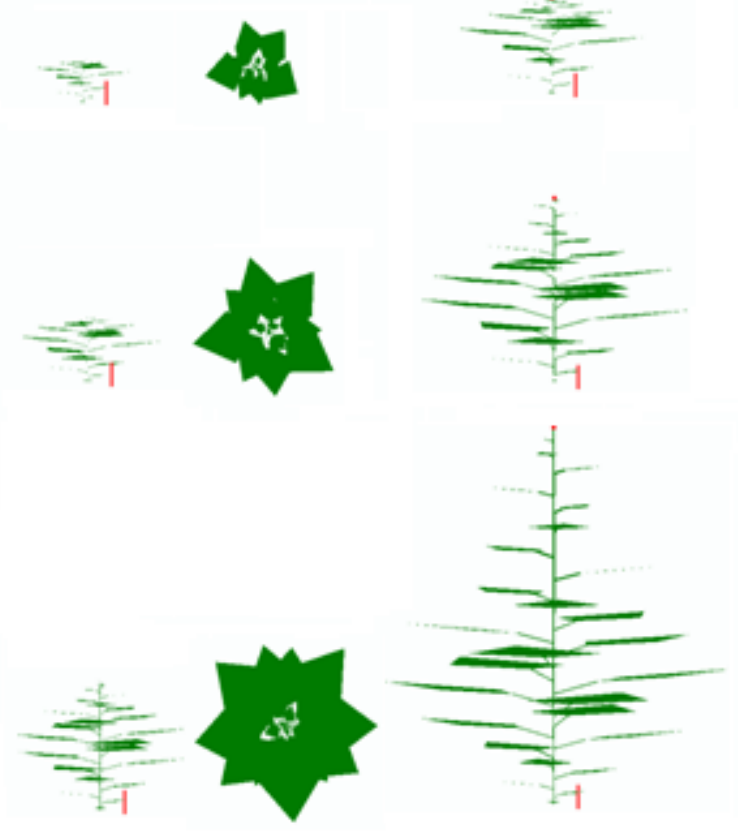
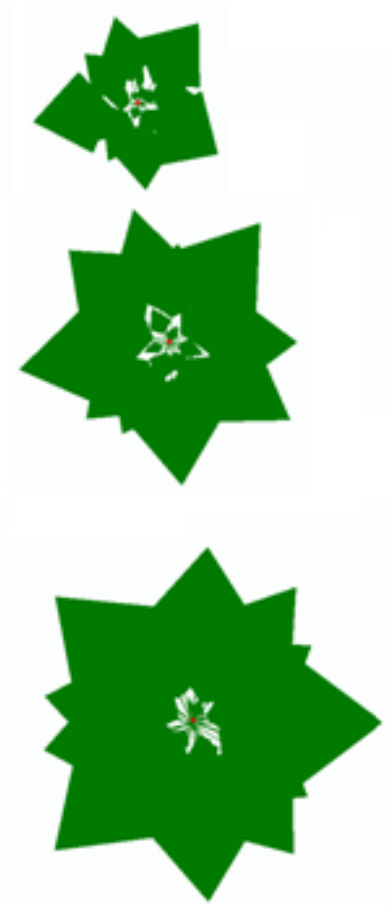

Figure 5. Side-view and top view of plant at different growth ages (Day20 and Day 32) under the three temperature regimes. Red bar is $10 \mathrm{~mm}$ in length. Red dot indicates the first formed flower of the whole plant.

\section{DISCUSSION AND CONCLUSIONS}

Two points have been clarified in this study. First, the phyllochron of parthenium weed has been determined. This outcome enables the prediction of parthenium weed growth under changed temperature regimes. Secondly, increase of temperature has been demonstrated to increase the canopy size and structure, and to accelerate the growth rate resulting in a shortened life cycle. Furthermore, the 3D canopy architecture model created from this study provides a visual presentation and description of parthenium weed growth under different temperatures.

It has also been determined that flowering is associated with the extension of the plants internodes. When internode length, under the different temperatures, is compared it can be seen illustrated this by showing greater maximum length on later (younger) internodes in temperature regimes $22 / 15^{\circ} \mathrm{C}$ and $27 / 20{ }^{\circ} \mathrm{C}$ where most plants produced flowers. By contrast, due to the temperature effect, most plants in temperature regime $22 / 15^{\circ} \mathrm{C}$ stayed in rosette stage and had not come to flowering stage when the experiment was finalised, which resulted in a shorter maximum internode length compared to the others.

Future work will be first to determine the effect of other climatic variables (precipitation and elevated $\mathrm{CO}_{2}$ ) on parthenium weed canopy structure, and to understand the potential impact of these changes in structure on pathogenic biocontrol agents' effectiveness and disease severity. This work will also be presented using 3D canopy models to provide a virtual understanding. Additional work may be to look into the detailed shape of leaves in order to refine models and to look into the structure of inflorescence and inflorescence leaves. 


\section{ACKNOWLEDGEMENT}

The authors acknowledge the kind assistance of people as followed: Mariano Trevino, Mark Mitchell, Patrick Rogers, Tod Eadie, Trevor Armstrong, and Yi Zhou.

\section{REFERENCES}

Bradley, B. A., Blumenthal, D. M., Wilcove, D. S., and Ziska, L. H. (2010). Predicting plant invasions in an era of global change. Trends in Ecology \& Evolution 25, 310-318.

Chakraborty, S. (2005). Potential impact of climate change on plant-pathogen interactions. Australasian Plant Pathology 34, 443-448.

Dale, I. J. (1981) Parthenium weed in the Americas. Australian Weeds 1, 8-14.

Doley, D. (1977) Parthenium weed (Parthenium hysterophorus L.): gas exchange characteristics as a basis for prediction of its geographical distribution. Australian Journal of Agricultural Research 28, 449-460.

Drouet, J. L. and Pagès, L. (2007). GRAAL-CN: a model of GRowth, Architecture and ALlocation for Carbon and Nitrogen dynamics within whole plants formalised at the organ level. Ecological Modelling 206, 231-249.

Hanan, J. (1997). Virtual plants- integrating architectural and physiological models. Environmental Modelling \& Software 12, 35-42.

Hanan, J., and Prusinkiewicz, P. (2008). Foreword: studying plants with functional-structural models. Functional Plant Biology 35, i-iii.

Hegde, B. A., and Patil, T. M. (1980). Physiological studies on Parthenium hysterophorus Linn. under different ecological conditions. Biovigyanam 6, 15-19.

Idso, K. E., and Idso, S. B. (1994). Plant responses to atmospheric $\mathrm{CO}_{2}$ enrichment in the face of environmental constraints: a review of the past 10 years' research. Agricultural and Forest Meteorology 69, 153-203.

Lindenmayer, A. (1968a). Mathematical models for cellular interactions in development I. Filaments with one-sided inputs. Journal of Theoretical Biology 18, 280-299.

Lindenmayer, A. (1968b). Mathematical models for cellular interactions in development II. Simple and branching filaments with two-sided inputs. Journal of Theoretical Biology 18, 300-315.

Manea, A., and Leishman, M. (2010). Competitive interactions between native and invasive exotic plant species are altered under elevated carbon dioxide. Oecologia, 1-10.

Manning, W. J., and Tiedemann, A. v. (1995). Climate change: Potential effects of increased atmospheric Carbon dioxide $\left(\mathrm{CO}_{2}\right)$, ozone $\left(\mathrm{O}_{3}\right)$, and ultraviolet-B (UV-B) radiation on plant diseases. Environmental Pollution 88, 219-245.

Matros, A., Amme, S., Kettig, B., Buck-Sorlin, G. H., Sonnewald, U., and Mock, H.-P. (2006). Growth at elevated $\mathrm{CO}_{2}$ concentrations leads to modified profiles of secondary metabolites in tobacco cv. SamsunNN and to increased resistance against infection with potato virus Y. Plant, Cell and Environment 29, 126-137.

Navie, S. C., McFadyen, R. E., Panetta, F. D., and Adkins, S. W. (1996). The biology of Australian weeds 27. Parthenium hysterophorus L. Plant Protection Quarterly 11, 76-88.

Navie, S. C., Panetta, F. D., McFadyen, R. E., and Adkins, S. W. (2005). The effect of CO2 enrichment on the growth of a C3 weed (Parthenium hysterophorus L.) and its competitive interaction with a $\mathrm{C} 4$ grass (Cenchrus ciliaris L.). Plant Protection Quarterly 20, 61-66.

Pachepsky, L. B., Kaul, M., Walthall, C., Lydon, J., Kong, H., and Daughtry, C. S. T. (2004). Soybean growth and development visualized with L-systems simulations: effect of temperature. International Journal of Biotronics 33, 31-47.

Pangga, I. B., Hanan, J., and Chakraborty, S. (2011). Pathogen dynamics in a crop canopy and their evolution under changing climate. Plant Pathology 60, 70-81.

Ress, M., and Lawton, J. H. 1993. What can models tell us? Pages 65-85 in L. Fowden, T. Mansfield, and J. Stoddart, eds. Plant adaptation to environmental stress. London, UK: Chapman and Hall.

Room, P. M., Hanan, J. S., and Prusinkiewicz, P. (1996). Virtual plants: New perspectives for ecologists, pathologists and agricultural scientists. Trends in Plant Science 1, 33-38.

Trudgill, D. L., Honek, A., Li, D., and Van Straalen, N. M. (2005). Thermal time - concepts and utility. Annals of Applied Biology 146, 1-14. 